\title{
Prevalence and correlates of food insecurity among Lebanese households with children aged 4-18 years: findings from a national cross-sectional study
}

\author{
Lamis Jomaa $^{1,2}$, Farah Naja ${ }^{1}$, Samer Kharroubi ${ }^{1}$ and Nahla Hwalla ${ }^{1, *}$ \\ 'Department of Nutrition and Food Sciences, Faculty of Agricultural and Food Sciences, American University of \\ Beirut, PO Box 1 1-0.236, Riad El Solh, Beirut, Lebanon: ${ }^{2}$ Refugee Health Program, Global Health Institute, American \\ University of Beirut, Beirut, Lebanon
}

Submitted 6 April 2018: Final revision received 8 October 2018: Accepted 17 October 2018: First published online 4 December 2018

\begin{abstract}
Objective: Food insecurity (FI) is a major public health problem in Lebanon, a small middle-income country with the highest refugee per capita concentration worldwide and prolonged political and economic challenges. The present study aimed to measure the prevalence and sociodemographic correlates of household FI and to explore the association of household FI with anthropometric measures of children and their mothers.

Design: Cross-sectional survey (2014-2015).

Setting: Lebanon.

Participants: Nationally representative sample of Lebanese households with 418-year-old-children and their mothers ( $n$ 1204).

Results: FI prevalence (95\% CI), measured using the Arabic-translated, validated Household Food Insecurity Access Scale, was found to be $49 \cdot 3$ (44.0, 54.6) \% in the study sample. Mild, moderate and severe FI were found in $7 \cdot 0(5 \cdot 5,9 \cdot 2) \%, 23 \cdot 3$ $(20 \cdot 1,26 \cdot 8) \%$ and $18.9(14.9,23.5) \%$ of households, respectively. Multiple regression analysis showed that low maternal and paternal education, unemployment and crowding were significant correlates of household FI $(P<0 \cdot 05)$. No significant associations were observed between FI and anthropometric measures of children and their mothers, after adjusting for other socio-economic correlates. Food-insecure households reported various mechanisms to cope with food shortage, such as reducing the number of meals/d (49.6\%), borrowing food $(54.4 \%)$, spending savings $(34.5 \%)$ and withdrawing children from schools (8.0\%).

Conclusions: FI exists among a remarkable proportion of Lebanese households with children. Correlates of household FI should be considered when designing social welfare policies and public health programmes to promote more sustainable, resilient and healthier livelihoods among vulnerable individuals.
\end{abstract}

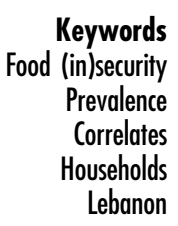

Food insecurity (FI) is defined as the situation where people do not have access, at all times, to sufficient, safe and nutritious food that meets their dietary needs for an active and healthy life while taking into consideration their food preferences ${ }^{(1)}$. According to the FAO, one in ten people in the world suffered from severe FI in 2016, corresponding to approximately 688 million people ${ }^{(2)}$. Despite international and national efforts to eliminate extreme poverty and increase global availability of food, FI remains a serious problem that affects populations worldwide, particularly those residing in low- and middleincome countries (LMIC) ${ }^{(2)}$. Further evidence highlights that FI is concentrated mostly in conflict-affected countries that witness political turmoil, financial instabilities and displacement ${ }^{(3)}$.

The Middle East and North Africa (MENA) region is considered one of the most food-insecure regions worldwide, with $11.8 \%$ experiencing severe FI in $2016^{(2)}$. The high prevalence of FI in the MENA region has been attributed to low agricultural production, heavy dependence on food imports, social inequities, economic instabilities and unstable political situations ${ }^{(4)}$. In fact, FI and poverty have been argued to be among the main drivers for the 'Arab Uprisings' movement that started in 
2010, which turned into armed conflicts and protracted crises $^{(5)}$. Today, the MENA region has the greatest number of conflicts and refugees worldwide ${ }^{(6)}$, with Lebanon, a small middle-income country with a population of just over 6 million people, having the highest per capita concentration of refugees worldwide ${ }^{(7)}$. Despite its pertinence, the literature exploring the prevalence and correlates of FI in Lebanon has been mostly focused on refugee populations, including those coming from Syria ${ }^{(7)}$, Palestine and $\operatorname{Iraq}^{(8,9)}$, with minimal attention being given to the Lebanese households and communities. The few studies published to date show that FI is not only a rural phenomenon ${ }^{(8)}$ but is also experienced among Lebanese urban residents ${ }^{(10,11)}$.

Exploring the factors that can contribute to household FI in conflict- and displacement-affected settings is challenging, yet it is of utmost importance to identify those most vulnerable to FI. Previous studies show that FI and hunger can be consequences of constrained financial resources; nevertheless, income and poverty measurements alone are not always determinants of $\mathrm{FI}^{(11,12)}$. Other demographic and socio-economic factors can come into play, such as household composition and size, educational attainment, employment status and number of children, including school-aged children ${ }^{(12)}$. In addition, households that are vulnerable to poverty and FI may adopt different temporary or permanent coping mechanisms to overcome shortage in economic resources and food ${ }^{(13)}$. These mechanisms can vary from dietary restrictions to begging, early marriage and dropping out of school, which can have serious implications on the overall health and well-being of vulnerable household members, particularly women and children ${ }^{(14,15)}$.

Studies have shown that household FI is associated with inadequate nutrient intakes ${ }^{(16,17)}$, increased risk of mental health problems and depression ${ }^{(18)}$, and poor pregnancy outcomes among women and mothers, including low birth weight and gestational diabetes ${ }^{(17)}$. In addition, FI has been associated with maternal thinness in Colombia and Cambodia ${ }^{(14,19)}$, yet with a higher risk of weight gain and obesity in higher-income countries ${ }^{(20)}$. The adverse consequences of FI on children's health and nutritional status have also been examined, such as increased risk of illnesses, nutrient deficiencies, lower physical and psychological functioning, and increased cognitive and behavioural problems ${ }^{(16,21,22)}$. Nevertheless, these studies have been mostly conducted in high-income countries with few studies exploring the effect of household FI on child health outcomes within LMIC settings ${ }^{(14,18,23)}$. It is also worth noting that these studies focus primarily on young children $(<5 \text { years old })^{(19,24)}$, with less emphasis being placed on older children ${ }^{(25)}$.

Recent evidence highlights the importance of considering school-aged children, who may be equally, if not even more vulnerable to the adverse consequences of household FI compared with their younger siblings ${ }^{(25-27)}$.
Older children may be at increased risk of health insults associated with FI due to their dependence on the table food available in the household compared with their younger siblings, who may be still protected nutritionally by breast-feeding and other early infant feeding practices ${ }^{(25)}$. In addition, school-aged children have higher nutritional needs, yet mothers may be less attentive to their dietary intakes or may have less control over their older children's choice of foods and beverages outside the home setting compared with the younger ones ${ }^{(27)}$.

To address this gap in the literature, the present study aimed to: (i) estimate the prevalence of FI using a nationally representative sample of Lebanese households with children aged 4-18 years and their mothers; (ii) examine the sociodemographic correlates of household FI in the study sample; (iii) explore the associations between household FI and anthropometric measurements of children and their mothers; and (iv) identify the coping mechanisms adopted by food-insecure households.

\section{Materials and methods}

\section{Study population}

Data for the present study were drawn from a crosssectional survey, the Lebanese Food and Nutrition Security Survey (L-FANUS), conducted on a nationally representative sample of Lebanese households with children aged 418 years. Data collection took place between December 2014 and November 2015, which overlapped with the fifth year of the Syrian crisis. A stratified cluster sampling strategy was followed, whereby the strata were the six Lebanese governorates and the clusters were drawn from the twenty-six districts ( $C a z a$ ) in Lebanon. The number of clusters per district differed depending on the population density in that district. In each district, households were selected based on a probability-proportional-to-size approach. A higher number of participating households was drawn from districts with higher population density using data from the Lebanese Central Administration of Statistics $^{(28)}$ and after consulting with a local statistics agency. Households were selected using a systematic sampling approach. Sample size calculations showed that a minimum of 1200 households was needed to provide $95 \% \mathrm{CI}$ for a FI prevalence estimate of $51.7 \%$ with $\pm 4 \%$ variation and a design effect of 2 . The estimate of $51.7 \%$ used in the sample size calculation was based on the FI estimate reported among a small sample of households in Lebanon $^{(29)}$.

For a household to be eligible, it had to include a mother and one child between 4 and 18 years of age who were present at the time of the interview. In cases where more than one child was eligible, only one was selected at random to participate in the study using the Kish $\operatorname{method}^{(30)}$. Inclusion criteria were having the mother and child be of Lebanese nationality, not suffering from any 
chronic disease, and not taking any medications that may interfere with their body composition or their overall nutritional status. Of the 4076 households that were contacted, 3147 accepted to participate in the study (response rate $=77 \%$ ) and 1221 households met the eligibility criteria. Of these, 1209 completed the interview. The main reasons for refusing to participate in the study were time constraints and disinterest in the study. Informed consent and assent were obtained from mothers and their children prior to their participation in the study.

\section{Data collection}

Face-to-face interviews with study participants were held in the household setting and lasted on average $45 \mathrm{~min}$. Mothers served as the main proxy for the household. The survey included sociodemographic questions such as age of mother and child, child's gender, number of children in the household, household income, educational level and employment status of parents, and region of residence (governorate). In addition, the total number of persons and rooms per household were collected to calculate crowding index. The latter was calculated as the total number of household members divided by the total number of rooms in a household (excluding kitchens, bathrooms and balconies) ${ }^{(31)}$. Households with fewer than two persons per room were considered to have a lower crowding index as compared with those with two or more persons per room. This index was used as a proxy measure of household socio-economic status in the present study, as it was previously used in Lebanon and provided reliable results ${ }^{(29,31,32)}$.

To measure household FI, the survey included nine questions from the Household Food Insecurity Access Scale (HFIAS). The HFIAS was originally developed by the US Agency for International Development-funded Food and Nutrition Technical Assistance Project ${ }^{(33)}$. This tool was previously translated to Arabic and validated in Lebanon, showing high internal consistency (Cronbach's $\alpha$ of 0.91 ) and reliability (intraclass correlation coefficient of $0 \cdot 58)^{(29)}$. This nine-question scale produces a total score between 0 and 27 with higher scores indicating greater FI; results from this scoring are used to categorize households into four levels of FI (food secure, mildly, moderately or severely food-insecure households) depending on the number of positive responses to questions related to severe conditions and as per the HFIAS measurement and indicator guide ${ }^{(33)}$.

The coping mechanisms of households in the study sample were assessed using an adapted version of the Coping Strategies Index (CSI). Households who reported that they had shortage in money and food in the past month completed this section of the survey. The adapted CSI tool included two sets of questions about the coping strategies adopted by households: (i) food-related strategies such as relying on less preferred and less expensive foods, borrowing food, limiting portion sizes at meal times and reducing number of meals eaten in a day; and (ii) asset-related strategies such as spending savings, selling jewellery or household goods (furniture, television, radio, etc.), selling assets (house, land, transportation mode), reducing essential non-food expenditures on health and education, withdrawing children from school and having children (6-15 years old) be involved in incomegenerating activities.

\section{Anthropometric measurements of mothers and cbildren}

Anthropometric assessments for study participants were conducted by trained dietitians using standard techniques and equipment. Participants were weighed on a digital scale (Seca model 770, Hamburg, Germany) to the nearest $0 \cdot 1 \mathrm{~kg}$ while wearing light clothing. Height was measured using a portable stadiometer (Seca model 213, Hamburg, Germany) to the nearest $0 \cdot 1 \mathrm{~cm}$ while not wearing shoes and in a standing position. Waist circumference was measured to the nearest $0 \cdot 1 \mathrm{~cm}$ using a plastic measuring tape at the midpoint between the bottom of the rib cage and the top of the iliac crest. All measurements were taken twice and the average of the two values was reported. BMI was calculated by dividing weight by height squared $\left(\mathrm{kg} / \mathrm{m}^{2}\right)$. Mothers were categorized as normal weight, overweight or obese based on the WHO classifications ${ }^{(34)}$. BMI-for-age $Z$-scores (BAZ) for children and adolescents were calculated using the WHO Anthro Plus software version 1.0.4 ${ }^{(35)}$. Children were classified as thin, normal weight, at risk of overweight (only for children $<5$ years), overweight and obese based on the WHO age-specific cut-offs $^{(36)}$. Height-for-age $Z$-score (HAZ) and weight-forage $Z$-score (WAZ) were calculated to assess undernutrition among children in the study sample. Stunting and underweight were defined as $\mathrm{HAZ}<-2$ and $\mathrm{WAZ}<-2$ compared with the WHO child growth standards, respectively ${ }^{(35)}$. In addition, waist-to-height ratio (WHtR) was calculated as waist circumference divided by height, both being measured in centimetres. The suggested cut-off point of $\mathrm{WHtR} \geq 0.5$ was used to identify children with elevated WHtR, an indicator of abdominal obesity among children ${ }^{(37)}$.

\section{Statistical analyses}

Descriptive statistics were reported as means with their standard errors for continuous variables and as frequencies and proportions for categorical variables. As noted earlier, households were recruited from the six Lebanese governorates, namely Beirut (the capital), Bekaa, Mount Lebanon, North of Lebanon, Nabatiyeh and South of Lebanon. The two governorates located in the southern regions of the country (Nabatiyeh and South of Lebanon) were grouped together for analysis. The results in the present study were weighted to account for the 
effect of the cluster sampling technique used in L-FANUS. The weighted analyses were conducted using the statistical software package Stata/SE version 12 . The prevalence of FI was reported at the national and governorate levels. The associations of sociodemographic and anthropometric characteristics of the study sample with the odds of household FI were conducted using simple and multiple logistic regressions. Anthropometric variables explored in the logistic regression models included BMI for mothers, and BAZ, WAZ, HAZ and WHtR for children. The outcome in these models was household FI, which was recoded into two categories: $0=$ food secure $v .1=$ food insecure (combined mildly, moderately and severely food-insecure households). All sociodemographic variables that were found significant in the simple logistic models were entered in the final multiple logistic regressions. Results from the logistic regression models were expressed as odds ratios with $95 \%$ confidence intervals. $P<0.05$ was considered statistically significant.

\section{Results}

Out of the 1209 households with children aged 4-18 years who took part in the study, only five households had incomplete sociodemographic and food security data and were thus excluded from the analyses. Table 1 shows the sociodemographic characteristics of the weighted study sample. On average, mother's age was 39.6 (SE 0.3 ) years and children were 10.9 (SE 0.2 ) years old, with an average of three children per household. The sample included an equal distribution of boys and girls (48.4 and 51.6\%, respectively). The educational levels of parents were found to be comparable, with $55.3 \%$ of households having fathers with intermediate school level education or less and $47.4 \%$ having mothers with a similar educational attainment. The majority of households had employed fathers (94\%), whereas about $24 \%$ of households had employed mothers. In addition, $26 \%$ had a crowding index of $\geq 2$ persons/room and $40 \%$ of households had monthly income less than \$US 663, a value slightly higher than the minimum wage salary in Lebanon of \$US 450 .

In terms of the anthropometric characteristics of the study sample, more than two-thirds of mothers were either overweight or obese $(68.5 \%)$ with the remaining $31.5 \%$ having normal body weight. For children ( $4-5$ years), $58 \cdot 2 \%$ were found to be of normal weight while the remaining children were classified as at risk of overweight (11.5\%), overweight (20.0\%) or obese (10.6\%). As for children above 5 years of age, approximately $56 \%$ were normal weight while $22 \%$ were overweight and $20 \%$ were obese. In addition, slightly less than a third of children in the study sample had an elevated WHtR (WHtR $\geq 0.5)$ and less than $5 \%$ of children were found to be either stunted or underweight using the age- and gender-specific growth charts.
Table 1 Sociodemographic and anthropometric characteristics of the study sample of Lebanese households with children aged 4-18 years ( $n$ 1204), 2014-2015†

\begin{tabular}{|c|c|c|}
\hline & $\begin{array}{l}\text { Mean or } \\
n\end{array}$ & $\begin{array}{l}\text { SE or } \\
\%\end{array}$ \\
\hline \multicolumn{3}{|l|}{ Sociodemographic characteristics } \\
\hline Child's age (years) & $10 \cdot 9$ & 0.18 \\
\hline Mother's age (years) & 39.6 & 0.32 \\
\hline Number of children & 3.1 & 0.08 \\
\hline \multicolumn{3}{|l|}{ Child's gender } \\
\hline Male & 582 & 48.4 \\
\hline Female & 621 & $51 \cdot 6$ \\
\hline \multicolumn{3}{|l|}{ Father's education level } \\
\hline Intermediate school or less & 658 & $55 \cdot 3$ \\
\hline High school/technical diploma & 367 & $30 \cdot 8$ \\
\hline University degree & 165 & 13.9 \\
\hline \multicolumn{3}{|l|}{ Mother's education level } \\
\hline Intermediate school or less & 571 & 47.4 \\
\hline High school/technical diploma & 400 & $33 \cdot 2$ \\
\hline University degree & 233 & 19.4 \\
\hline \multicolumn{3}{|l|}{ Father's employment status } \\
\hline Unemployed & 69 & $5 \cdot 9$ \\
\hline Employed & 1109 & 94.1 \\
\hline \multicolumn{3}{|l|}{ Mother's employment status } \\
\hline Unemployed & 916 & $76 \cdot 3$ \\
\hline Employed & 285 & $23 \cdot 7$ \\
\hline \multicolumn{3}{|l|}{ Crowding index } \\
\hline$<2$ persons/room & 894 & 74.4 \\
\hline$\geq 2$ persons/room & 308 & $25 \cdot 6$ \\
\hline \multicolumn{3}{|l|}{$\begin{array}{l}\text { Household monthly income (Lebanese } \\
\text { pounds) }\end{array}$} \\
\hline$<1000000$ (equivalent to $<\$$ US 663) & 470 & $39 \cdot 8$ \\
\hline $1000000-2000000$ (\$US 663-1326) & 441 & $37 \cdot 3$ \\
\hline$>2000000$ (equivalent to $>\$$ US 1326) & 270 & $22 \cdot 9$ \\
\hline \multicolumn{3}{|l|}{ Region of residence (governorate) } \\
\hline Beirut & 62 & $5 \cdot 1$ \\
\hline Bekaa & 215 & $18 \cdot 1$ \\
\hline Mount Lebanon & 468 & 38.9 \\
\hline North of Lebanon & 198 & $16 \cdot 0$ \\
\hline South of Lebanon & 261 & 21.9 \\
\hline \multicolumn{3}{|l|}{ Anthropometric measures $\ddagger$} \\
\hline \multicolumn{3}{|l|}{ Mother's BMI } \\
\hline Normal weight $\left(18.5-24.9 \mathrm{~kg} / \mathrm{m}^{2}\right) \S$ & 378 & 31.5 \\
\hline Overweight $\left(25.0-29.9 \mathrm{~kg} / \mathrm{m}^{2}\right)$ & 422 & $35 \cdot 2$ \\
\hline Obese $\left(\geq 30.0 \mathrm{~kg} / \mathrm{m}^{2}\right)$ & 399 & $33 \cdot 3$ \\
\hline \multicolumn{3}{|l|}{ Children (4-5 years) } \\
\hline \multicolumn{3}{|l|}{ BMI status } \\
\hline Thin $(B A Z<-2)$ & 0 & 0.0 \\
\hline Normal $(-2 \leq \mathrm{BAZ} \leq+1)$ & 45 & $58 \cdot 2$ \\
\hline At risk of overweight $(+1<\mathrm{BAZ} \leq+2)$ & 9 & 11.5 \\
\hline Overweight $(+2<\mathrm{BAZ} \leq+3)$ & 16 & $20 \cdot 0$ \\
\hline Obese $(\mathrm{BAZ}>+3)$ & 8 & $10 \cdot 6$ \\
\hline \multicolumn{3}{|l|}{ Children ( $>5$ years) } \\
\hline \multicolumn{3}{|l|}{ BMI status } \\
\hline Thin $(B A Z<-2)$ & 16 & 1.5 \\
\hline Normal weight $(-2 \leq \mathrm{BAZ} \leq+1)$ & 617 & $55 \cdot 8$ \\
\hline Overweight $(+1<B \bar{A} Z \leq+2)$ & 249 & $22 \cdot 5$ \\
\hline Obese $(\mathrm{BAZ}>+2)$ & 223 & $20 \cdot 2$ \\
\hline WHtR $\geq 0.5$ (elevated) $\|$ & 347 & 31.5 \\
\hline $\mathrm{HAZ}<-2$ (stunted) & 57 & 4.8 \\
\hline WAZ $<-2$ (underweight) & 12 & $2 \cdot 4$ \\
\hline
\end{tabular}

BAZ, BMI-for-age Z-score; WHtR, waist-to-height ratio; HAZ, height-for-age Z-score; WAZ, weight-for-age Z-score.

†Continuous variables are presented as means with their $\mathrm{SE}$, whereas categorical variables are reported as $n$ and \%.

$\ddagger$ Anthropometric measurements of mothers and children were categorized based on WHO classification ${ }^{(34-36)}$.

§Underweight mothers $(n 11)$ were added to the normal-weight group. UWHtR was calculated only for children aged $>5$ years.

IWAZ was calculated only for children aged $<10$ years as per the WHO growth charts. 
The prevalence of FI reported in the present study sample was $49 \cdot 3 \%$ (95\% CI 44.0, 54.6\%). Approximately $7 \%$ of households (95\% CI 5.5, 9.2\%) were mildly food insecure, $23 \cdot 3 \%$ (95\% CI 20.1, 26.8\%) were moderately food insecure and $18.9 \%$ (95\% CI 14.9, 23.5\%) were severely food insecure. Using simple logistic regression analysis, the correlates of FI were mother's age, number of children, mother and father's educational attainment and employment status, region of residence, crowding index and income (Table 2). Results from the multiple logistic regression model showed that households with employed fathers and employed mothers were significantly less likely to be food insecure than those with unemployed fathers and mothers $(\mathrm{OR}=0.35 ; 95 \% \mathrm{CI} 0.17,0.73$ and $\mathrm{OR}=0.54 ; 95 \% \mathrm{CI} 0.35,0.84$, respectively). In addition, households with higher parental educational levels were significantly less likely to be food insecure than households with lower parental educational levels $(P<0.05$; Table 2). Households with higher crowding ( $\geq 2$ persons/ room) remained significantly associated with higher odds of household FI (OR = 1·86; $95 \%$ CI 1·26, 2.75), even after adjusting for other socio-economic correlates. Household income was excluded from the multiple logistic regression models to avoid multicollinearity with crowding index. Data from previous studies also showed that crowding index is less subject to reporting bias than income, and it can be a more reliable measure of a household's socioeconomic status ${ }^{(38)}$.

Table 3 presents the associations between household FI status and the anthropometric measures of mothers and children. Using simple logistic regression analysis, FI was found to be 1.79 times more likely among households in which the mothers were obese as compared with households in which the mothers had normal weight. However, this association was no longer statistically significant after adjusting for other sociodemographic correlates of FI. No other significant associations were observed between household FI and anthropometric measurements of children in the multiple logistic regression models.

Table 4 presents coping mechanisms of food-insecure households in the study sample who reported that they did not have enough food or money to buy food for their family members during the past month. The most commonly adopted coping strategies reported by foodinsecure households (whether sometimes, often or always in the past month) included food-related strategies such as relying on less preferred and less expensive foods ( $81.2 \%$ of households), borrowing food or relying on help from a friend or relative to secure food $(54.4 \%)$, reducing the number of meals eaten per day (49.6\%) and restricting the consumption of adults to secure food for children (45.5\%). Food-insecure households also resorted to various asset-related strategies to cope with their condition, from spending savings, selling assets (jewellery, household goods, house/land) and reducing essential non-food expenditures on education and health, to more severe coping mechanisms such as withdrawing children from school $(8.0 \%)$ and involving them in income-generating activities (8.7\%).

\section{Discussion}

The present study is the first to explore the prevalence and correlates of FI among a nationally representative sample of Lebanese households with children aged 4-18 years. Findings show that almost half of the study sample was food insecure in 2015, with more than $42.2 \%$ being moderately to severely food insecure. The overall FI prevalence in the present study was found to be comparable to those reported in previous studies conducted among smaller samples of Lebanese households in the South of Lebanon and Greater Beirut regions (42 and 50\%, respectively $)^{(10,11)}$. Nevertheless, FI prevalence in our study sample remained higher than those reported in other middle-income countries in the MENA region, including Jordan, Turkey and Egypt $(17-32 \%)^{(39-41)}$; and it was much higher than prevalence rates reported in highincome countries, such as the USA, Canada and France, with only $5-15 \%$ of their respective populations experiencing $\mathrm{FI}^{(12,42,43)}$

The high prevalence of FI in the study sample needs to be considered in the light of the country's historical and current conditions. Lebanon has undergone persistent conflicts and volatile political and economic conditions for more than three decades, and since 2011 it has been further challenged with the influx of large numbers of Syrian refugees into the country. The prolonged displacement of Syrian refugees has added major strain on the Lebanese economy and infrastructure and may have jeopardized the food security of its population ${ }^{(44)}$. Data from the 2007 national report on poverty, growth and income distribution in Lebanon showed that approximately $30 \%$ of the population lived below the poverty line, and $8 \%$ of the Lebanese population continued to live in extreme poverty (below \$US $2 \cdot 40 /$ person per $\mathrm{d}^{(45,46)}$ ). More recent data from the World Bank showed that the number of people living under the poverty line in Lebanon has risen by $66 \%$ since the start of the Syrian refugee crisis, pushing almost 170000 Lebanese into poverty and doubling unemployment to over $20 \%$, especially among the unskilled youth $^{(44,46)}$. In parallel, 1.3 million people were identified to be in need of food post the crisis, of which 182000 were from the most vulnerable Lebanese communities hosting Syrian refugees and displaced families ${ }^{(47)}$. All these conditions and others may have contributed to the economic challenges and FI status of the most vulnerable households in the country, particularly those with children.

When exploring correlates of FI, findings from the present study showed that household FI was associated with several sociodemographic characteristics, including lower parental educational attainment and unemployment 
Table 2 Associations of sociodemographic characteristics with the odds of household food insecurity in the study sample of Lebanese households with children aged 4-18 years ( $n$ 1204), 2014-2015†

\begin{tabular}{|c|c|c|c|c|c|c|c|c|c|c|c|c|}
\hline \multirow[b]{2}{*}{ Sociodemographic characteristic } & \multicolumn{2}{|c|}{$\begin{array}{l}\text { Food secure } \\
\qquad(n \text { 569) }\end{array}$} & \multicolumn{2}{|c|}{$\begin{array}{l}\text { Mildly food secure } \\
\qquad(n 100)\end{array}$} & \multicolumn{2}{|c|}{$\begin{array}{l}\text { Moderately food insecure } \\
\qquad(n \text { 274) }\end{array}$} & \multicolumn{2}{|c|}{$\begin{array}{l}\text { Severely food insecure } \\
\qquad(n 261)\end{array}$} & \multirow[b]{2}{*}{ OR } & \multirow[b]{2}{*}{$95 \% \mathrm{Cl}$} & \multirow[b]{2}{*}{ Adjusted OR§ } & \multirow[b]{2}{*}{$95 \% \mathrm{Cl}$} \\
\hline & Mean or $n$ & SE or $\%$ & Mean or $n$ & SE or $\%$ & Mean or $n$ & SE or $\%$ & Mean or $n$ & SE or $\%$ & & & & \\
\hline Child's age (years) & $10 \cdot 7$ & 0.29 & $10 \cdot 8$ & 0.52 & $11 \cdot 0$ & 0.31 & $11 \cdot 7$ & 0.29 & 1.04 & $0.99,1.08$ & - & - \\
\hline Mother's age (years) & 39.0 & 0.48 & 39.5 & 0.78 & $40 \cdot 1$ & 0.58 & $40 \cdot 6$ & 0.57 & $1.02^{\star}$ & $1.00,1.04$ & 1.00 & $0.98,1.03$ \\
\hline Number of children & $2 \cdot 8$ & 0.06 & $2 \cdot 8$ & 0.11 & 3.3 & 0.12 & 3.6 & 0.22 & $1 \cdot 38^{\star *}$ & $1.21,1.56$ & $1 \cdot 10$ & $0.97,1.26$ \\
\hline \multicolumn{13}{|l|}{ Child's gender } \\
\hline Male & 278 & $48 \cdot 9$ & 50 & $50 \cdot 1$ & 120 & 43.7 & 137 & $52 \cdot 4$ & 1.00 & Ref. & - & - \\
\hline Female & 290 & $51 \cdot 1$ & 50 & 49.9 & 154 & $56 \cdot 3$ & 124 & 47.6 & 1.04 & $0.78,1.39$ & - & - \\
\hline \multicolumn{13}{|l|}{ Father's education level } \\
\hline Intermediate school or less & 230 & 40.5 & 58 & $58 \cdot 1$ & 189 & $69 \cdot 7$ & 194 & 76.5 & 1.00 & Ref. & 1.00 & Ref. \\
\hline High school/technical diploma & 218 & 38.6 & 30 & 30.5 & 65 & $24 \cdot 2$ & 45 & 17.9 & $0.34^{\star *}$ & $0.23,0.49$ & $0.58^{\star *}$ & $0.39,0.87$ \\
\hline University degree & 118 & $20 \cdot 9$ & 11 & 11.4 & 17 & $6 \cdot 1$ & 15 & $5 \cdot 6$ & $0.19^{\star \star}$ & $0.11,0.32$ & $0.43^{\star \star}$ & $0.23,0.79$ \\
\hline \multicolumn{13}{|l|}{ Mother's education level } \\
\hline Intermediate school or less & 160 & 28.0 & 52 & $51 \cdot 7$ & 181 & $66 \cdot 0$ & 195 & 74.8 & 1.00 & Ref. & 1.00 & Ref. \\
\hline High school/technical diploma & 246 & 43.3 & 32 & $31 \cdot 8$ & 59 & $21 \cdot 4$ & 56 & $21 \cdot 3$ & $0.22^{\star \star}$ & $0.16,0.31$ & $0.31^{\star \star}$ & $0.21,0.47$ \\
\hline University degree & 163 & $28 \cdot 7$ & 16 & $16 \cdot 5$ & 34 & $12 \cdot 6$ & 10 & 3.9 & $0 \cdot 14^{\star *}$ & $0.09,0.22$ & $0.30^{\star \star}$ & $0.18,0.50$ \\
\hline \multicolumn{13}{|l|}{ Father's employment status } \\
\hline Unemployed & 14 & 2.5 & 7 & $7 \cdot 1$ & 14 & $5 \cdot 3$ & 39 & $15 \cdot 7$ & 1.00 & Ref. & 1.00 & Ref. \\
\hline Employed & 547 & 97.5 & 91 & $92 \cdot 9$ & 256 & 94.7 & 210 & $84 \cdot 3$ & $0.24^{\star *}$ & $0.11,0.51$ & $0.35^{\star \star}$ & $0.17,0.73$ \\
\hline \multicolumn{13}{|l|}{ Mother's employment status } \\
\hline Unemployed & 382 & $67 \cdot 3$ & 83 & 83.6 & 228 & 83.1 & 233 & $89 \cdot 3$ & 1.00 & Ref. & 1.00 & Ref. \\
\hline Employed & 185 & $32 \cdot 7$ & 16 & $16 \cdot 4$ & 46 & $16 \cdot 9$ & 28 & $10 \cdot 7$ & $0.35^{\star *}$ & $0.24,0.50$ & $0.54^{\star \star}$ & $0.35,0.84$ \\
\hline \multicolumn{13}{|l|}{ Crowding index } \\
\hline$<2$ persons/room & 485 & $85 \cdot 6$ & 85 & $85 \cdot 2$ & 178 & $65 \cdot 2$ & 135 & 51.9 & 1.00 & Ref. & 1.00 & Ref. \\
\hline$\geq 2$ persons/room & 82 & 14.4 & 15 & $14 \cdot 8$ & 96 & 34.8 & 126 & $48 \cdot 1$ & $3.48^{\star *}$ & $2.41,5.03$ & $1.86^{\star \star}$ & $1 \cdot 26,2 \cdot 75$ \\
\hline \multicolumn{13}{|l|}{ Region of residence (governorate) } \\
\hline Beirut & 32 & $5 \cdot 6$ & 5 & $4 \cdot 1$ & 8 & 3.0 & 17 & 6.6 & 1.00 & Ref. & 1.00 & Ref. \\
\hline Bekaa & 114 & $20 \cdot 0$ & 15 & 14.9 & 58 & $21 \cdot 1$ & 28 & $10 \cdot 6$ & 1.00 & $0.52,1.93$ & 0.73 & $0.38,1.41$ \\
\hline Mount Lebanon & 225 & 39.6 & 50 & $50 \cdot 2$ & 100 & $36 \cdot 5$ & 93 & $35 \cdot 7$ & 1.20 & $0.72,2.00$ & 1.40 & $0.83,2.51$ \\
\hline North of Lebanon & 65 & 11.4 & 11 & 11.4 & 45 & $16 \cdot 3$ & 77 & 29.6 & $2 \cdot 30^{*}$ & $1.08,4.73$ & 1.30 & $0.72,2.29$ \\
\hline South of Lebanon & 133 & $23 \cdot 4$ & 19 & $19 \cdot 4$ & 63 & $23 \cdot 1$ & 46 & $17 \cdot 5$ & $1 \cdot 10$ & $0.59,1.99$ & 0.72 & $0.37,1.42$ \\
\hline \multicolumn{13}{|c|}{ Household monthly income (Lebanese pounds) } \\
\hline$<1000000$ & 105 & 18.9 & 45 & $46 \cdot 8$ & 159 & 58.9 & 177 & 68.5 & 1.00 & Ref. & - & - \\
\hline $1000000-2000000$ & 232 & $41 \cdot 7$ & 38 & $39 \cdot 0$ & 98 & $36 \cdot 4$ & 68 & $26 \cdot 2$ & $0.25^{\star *}$ & $0.16,0.37$ & - & - \\
\hline$>2000000$ & 219 & $39 \cdot 3$ & 14 & $14 \cdot 2$ & 13 & 4.7 & 13 & $5 \cdot 2$ & $0.05^{\star \star}$ & $0.03,0.09$ & - & - \\
\hline
\end{tabular}

Ref., reference category.

${ }^{*} P<0.05,{ }^{\star \star} P<0.01$.

†Continuous variables are presented as means with their SE, whereas categorical variables are reported as $n$ and \%.

$\neq O R$ of the dependent variable (food-insecure $v$. food-secure households) are presented with $95 \% \mathrm{Cl}$ using simple logistic regression. The food-insecure category included mildly, moderately and severely food-insecure households.

$\S$ Adjusted OR are presented with $95 \% \mathrm{Cl}$ using multiple logistic regression analysis. The models were adjusted for sociodemographic characteristics found to be significant correlates of food insecurity (mother's age, number of children, parental education and employment status, region of residence and crowding index), except for income to avoid multicollinearity.

$\|$ Household income was excluded from the multiple logistic regressions to avoid multicollinearity with crowding index. 
Table 3 Associations of anthropometric measures with the odds of household food insecurity in the study sample of Lebanese households with children aged 4-18 years ( $n$ 1204), 2014-2015†

\begin{tabular}{|c|c|c|c|c|c|c|c|c|c|c|c|c|}
\hline \multirow[b]{2}{*}{ Anthropometric measure $†$} & \multicolumn{2}{|c|}{$\begin{array}{l}\text { Food } \\
\text { secure } \\
\text { (n 569) }\end{array}$} & \multicolumn{2}{|c|}{$\begin{array}{c}\text { Mildly } \\
\text { food } \\
\text { insecure } \\
(n 100)\end{array}$} & \multicolumn{2}{|c|}{$\begin{array}{l}\text { Moderately } \\
\text { food } \\
\text { insecure } \\
(n 274)\end{array}$} & \multicolumn{2}{|c|}{$\begin{array}{c}\text { Severely } \\
\text { food } \\
\text { insecure } \\
(n 261)\end{array}$} & \multirow[b]{2}{*}{ OR $\ddagger$} & \multirow[b]{2}{*}{$95 \% \mathrm{Cl}$} & \multirow{2}{*}{$\begin{array}{l}\text { Adjusted } \\
\text { OR§ }\end{array}$} & \multirow[b]{2}{*}{$95 \% \mathrm{Cl}$} \\
\hline & $n$ & $\%$ & $n$ & $\%$ & $n$ & $\%$ & $n$ & $\%$ & & & & \\
\hline \multicolumn{13}{|l|}{ Mother's BMI } \\
\hline Normal weight $\left(18.5-24.9 \mathrm{~kg} / \mathrm{m}^{2}\right) \|$ & 200 & $35 \cdot 3$ & 35 & 35.5 & 68 & $25 \cdot 1$ & 72 & $27 \cdot 7$ & 1.00 & Ref. & 1.00 & Ref. \\
\hline Overweight $\left(25.0-29.9 \mathrm{~kg} / \mathrm{m}^{2}\right)$ & 209 & $36 \cdot 9$ & 37 & $37 \cdot 0$ & 93 & $34 \cdot 1$ & 82 & 31.5 & $1 \cdot 16$ & $0.79,1.71$ & 1.01 & $0.67,1.52$ \\
\hline Obese $\left(\geq 30.0 \mathrm{~kg} / \mathrm{m}^{2}\right)$ & 157 & $27 \cdot 8$ & 28 & $27 \cdot 6$ & 112 & 40.8 & 106 & 40.7 & $1.79^{\star \star}$ & $1 \cdot 16,2 \cdot 76$ & 1.39 & $0.84,2.29$ \\
\hline \multicolumn{13}{|l|}{ Children ( $4-5$ years) } \\
\hline \multicolumn{13}{|l|}{ BMI status } \\
\hline Normal $(-2 \leq \mathrm{BAZ} \leq+1)$ & 26 & $62 \cdot 0$ & 3 & 29.2 & 2 & $72 \cdot 9$ & 3 & $47 \cdot 2$ & 1.00 & Ref. & 1.00 & Ref. \\
\hline $\begin{array}{l}\text { At risk of overweight/overweight } \\
(B A Z>+1)\end{array}$ & 16 & $38 \cdot 0$ & 8 & $70 \cdot 8$ & 2 & $27 \cdot 1$ & 6 & $52 \cdot 8$ & $1 \cdot 28$ & $0 \cdot 75,2 \cdot 18$ & 1.38 & $0.64,2.94$ \\
\hline \multicolumn{13}{|l|}{ Children ( $>5$ years) } \\
\hline \multicolumn{13}{|l|}{ BMI status } \\
\hline Normal weight $(B A Z \leq+1)$ & 300 & $58 \cdot 2$ & 51 & $57 \cdot 1$ & 142 & 55.4 & 140 & 57.5 & 1.00 & Ref. & 1.00 & Ref. \\
\hline Overweight $(+1<\mathrm{BAZ} \leq+2)$ & 116 & 22.5 & 23 & $25 \cdot 9$ & 59 & $23 \cdot 1$ & 50 & $20 \cdot 7$ & 1.03 & $0.65,1.64$ & 1.05 & $0.61,1.79$ \\
\hline Obese $(\mathrm{BAZ}>+2)$ & 100 & $19 \cdot 3$ & 15 & $17 \cdot 0$ & 56 & 21.5 & 53 & 21.8 & $1 \cdot 12$ & $0.76,1.64$ & 1.31 & $0.84,2.03$ \\
\hline \multicolumn{13}{|l|}{ WHtRI } \\
\hline $\mathrm{WHtR}<0.5$ & 367 & 71.2 & 64 & $72 \cdot 8$ & 168 & $65 \cdot 0$ & 155 & 63.9 & 1.00 & Ref. & 1.00 & Ref. \\
\hline \multicolumn{12}{|l|}{ HAZ } & $0.83,1.83$ \\
\hline $\begin{array}{l}\mathrm{HAZ}<-2 \text { (stunted) } \\
\mathrm{HAZ} \geq-2\end{array}$ & $\begin{array}{r}30 \\
534\end{array}$ & $\begin{array}{r}5 \cdot 3 \\
94 \cdot 7\end{array}$ & $\begin{array}{r}2 \\
98\end{array}$ & $\begin{array}{r}1 \cdot 9 \\
98 \cdot 1\end{array}$ & $\begin{array}{r}5 \\
263\end{array}$ & $\begin{array}{r}1.9 \\
98.1\end{array}$ & $\begin{array}{r}21 \\
238\end{array}$ & $\begin{array}{r}8.0 \\
92.0\end{array}$ & $\begin{array}{l}1.00 \\
1.27\end{array}$ & $\begin{array}{c}\text { Ref. } \\
0.06,2.78\end{array}$ & $\begin{array}{l}1.00 \\
1.61\end{array}$ & $\begin{array}{c}\text { Ref. } \\
0.70,3.87\end{array}$ \\
\hline \multicolumn{13}{|l|}{ WAZ†† } \\
\hline WAZ $<-2$ (underweight) & 7 & $2 \cdot 7$ & 2 & $4 \cdot 6$ & 0 & 0.0 & 3 & 3.6 & 1.00 & Ref. & 1.00 & Ref. \\
\hline$W A Z \geq-2$ & 249 & $92 \cdot 3$ & 39 & $95 \cdot 4$ & 109 & $100 \cdot 0$ & 91 & $96 \cdot 4$ & 1.42 & $0.25,7.97$ & 1.59 & $0.38,6.61$ \\
\hline
\end{tabular}

BAZ, BMI-for-age Z-score; WHtR, waist-to-height ratio; HAZ, height-for-age Z-score; WAZ, weight-for-age Z-score; Ref., reference category.

${ }^{*} P<0.05,{ }^{*} P<0.01$.

†Anthropometric measurements of mothers and children were categorized based on WHO classification ${ }^{(34-36)}$.

fOR of the dependent variable (food-insecure $v$. food-secure households) are presented with $95 \% \mathrm{Cl}$ using simple logistic regression. The food-insecure category included mildly, moderately and severely food-insecure households.

$\S A d j u s t e d$ OR are presented with $95 \% \mathrm{Cl}$ using multiple logistic regression analysis. The models were adjusted for sociodemographic characteristics found to be significant correlates of food insecurity (mother's age, number of children, parental education and employment status, region of residence and crowding index), except for income to avoid multicollinearity.

$\|$ Underweight mothers ( $n$ 11) were added to the normal-weight group.

IWHtR was calculated for children aged $>5$ years only.

††WAZ was calculated only for children aged $<10$ years as per the WHO growth charts.

Table 4 Coping mechanisms adopted by food-insecure households who reported that they did not have enough food or money to buy food for their family members in the past month $(n 506)$ in the study sample of Lebanese households with children aged $4-18$ years, 2014-2015

\begin{tabular}{|c|c|c|c|c|c|c|c|c|}
\hline \multirow[b]{2}{*}{ Coping strategy } & \multicolumn{2}{|c|}{ Always } & \multicolumn{2}{|c|}{ Often } & \multicolumn{2}{|c|}{ Sometimes } & \multicolumn{2}{|c|}{ Never } \\
\hline & $n$ & $\%$ & $n$ & $\%$ & $n$ & $\%$ & $n$ & $\%$ \\
\hline \multicolumn{9}{|l|}{ Food-related strategies } \\
\hline Relied on less preferred and less expensive foods & 150 & $29 \cdot 8$ & 125 & $24 \cdot 8$ & 134 & $26 \cdot 6$ & 95 & $18 \cdot 8$ \\
\hline Borrowed food or relied on help from a friend/relative & 101 & $20 \cdot 0$ & 66 & $13 \cdot 1$ & 107 & $21 \cdot 2$ & 230 & $45 \cdot 6$ \\
\hline Limited portion size at meal times & 31 & $6 \cdot 2$ & 50 & $9 \cdot 9$ & 89 & $17 \cdot 7$ & 333 & $66 \cdot 2$ \\
\hline Restricted consumption by adults for small children to eat & 30 & 3.0 & 61 & $12 \cdot 1$ & 138 & $27 \cdot 4$ & 274 & 54.5 \\
\hline Reduced number of meals eaten in a day & 41 & $8 \cdot 1$ & 74 & 14.7 & 135 & $26 \cdot 8$ & 254 & $50 \cdot 4$ \\
\hline Sent family members eat elsewhere & 23 & 4.6 & 29 & $5 \cdot 8$ & 66 & 13.2 & 382 & 76.4 \\
\hline Borrowed money to buy food & 21 & $4 \cdot 2$ & 45 & $9 \cdot 0$ & 49 & $9 \cdot 8$ & 387 & $77 \cdot 1$ \\
\hline \multicolumn{9}{|l|}{ Asset-related and other coping strategies } \\
\hline Spent savings & 70 & 13.9 & 37 & $7 \cdot 4$ & 66 & $13 \cdot 1$ & 329 & 65.5 \\
\hline Sold jewellery or household goods (furniture, television, radio, etc.) & 43 & 8.5 & 22 & $4 \cdot 3$ & 55 & $10 \cdot 9$ & 386 & $76 \cdot 3$ \\
\hline Sold assets: house or land & 15 & 3.0 & 5 & 1.0 & 8 & 1.6 & 476 & 94.4 \\
\hline Sold assets: transportation mode & 3 & 0.6 & 2 & 0.4 & 6 & 1.2 & 493 & $97 \cdot 8$ \\
\hline Reduced essential non-food expenditures such as education, health & 55 & $11 \cdot 0$ & 33 & $6 \cdot 6$ & 77 & $15 \cdot 3$ & 337 & $67 \cdot 1$ \\
\hline Withdrew children from school & 26 & $5 \cdot 2$ & 7 & 1.4 & 7 & 1.4 & 463 & $92 \cdot 0$ \\
\hline Involved schoolchildren (6-15 years old) in income generation & 24 & $4 \cdot 8$ & 7 & 1.4 & 13 & 2.6 & 461 & $91 \cdot 3$ \\
\hline
\end{tabular}


together with higher household crowding. These results were in line with a study conducted in Lebanon on a smaller sample of households with young children $(<2$ years) showing significant associations between HFIAS scores and monthly income $(r=-0.45)$, crowding index $(r=0 \cdot 3)$, and mother's and father's educational levels $(r=-0.47 \text { and }-0.22 \text {, respectively })^{(8)}$. Similarly, lower odds of FI were previously associated with higher maternal education and household incomes among Lebanese households in the Greater Beirut region ${ }^{(9)}$. Evidence from other middle- and higher-income countries corroborates our findings showing that low educational attainment, unemployment, household composition and size, and having more children, including school-going children, were strong correlates of $\mathrm{FI}^{(12,23,48)}$.

Findings from the present study show that foodinsecure households resorted to various food- and assetbased coping mechanisms, such as reducing the number and portion size of meals consumed per day, borrowing food or money to buy food, spending savings, and reducing essential non-food expenditures such as on education and health. Similar coping strategies were previously reported among Syrian, Iraqi and Palestinian refugees in Lebanon $^{(7-9)}$, such as borrowing money, accepting a gift or donation, and consuming cheaper food items. The adoption of such mechanisms among households with children is particularly alarming, as it can have serious detrimental effects on the physical, cognitive and psychological health of children in the short and long run, and it warrants further attention ${ }^{(18,22,25)}$.

The associations between household FI and the anthropometric measures of mothers and children were also explored in the present study. Although FI was 1.79 times more common among households in which the mothers were obese compared with households with normal-weight mothers, this association was no longer statistically significant after adjusting for other socioeconomic covariates. These results were in contrast to those reported earlier in Beirut showing a significant association between household FI and maternal obesity (OR $=1.73 ; 95 \%$ CI 1.02, 2.92). Given that household FI was found to be significantly associated with maternal education and employment status in the present study, adjusting for these variables in the regression models may have attenuated the association between FI and obesity. According to a recent study conducted using national health surveys from thirty-eight LMIC, the formal employment of mothers was found to be significantly associated with higher odds of overweight, yet the magnitude of the association was affected by the educational attainment of mothers and not the countries' gross domestic product or urbanization ${ }^{(49)}$. These results may explain why the relationship between FI and maternal obesity is less consistent in $\mathrm{LMIC}^{(39,49)}$ compared with the strong evidence from high-income countries $^{(16,50)}$.
A high prevalence of overweight and obesity among 4-18-year-old children was observed in the present study ( 22.5 and $20.2 \%$, respectively), yet no significant associations were observed between household FI and childhood obesity. A previous national study conducted in Lebanon showed a similar high prevalence of overweight and obesity among 6-19-year-old children (34.8 and 13.2\%, respectively). In addition, maternal education and employment status were associated with higher odds of overweight and obesity, respectively, among 6-11-year-old children, but not among older children (12-19 years old $)^{(32)}$. The scientific literature shows mixed evidence with respect to the relationship between FI and obesity among children and adolescents from various contexts ${ }^{(50,51)}$. Thus, it is critical to explore the underlying mechanisms that can help explain the FI-obesity paradox and devise evidencebased strategies to curb the rising rates of paediatric overweight and obesity, particularly in LMIC settings.

The current study has a number of strengths. It is the first to explore the prevalence and correlates of household FI among a representative sample of Lebanese households with children. The demographic and socio-economic characteristics of the study sample were found to be comparable to national figures most recently available in Lebanon ${ }^{(47,51)}$. Other strengths of the study include the use of a culturally sensitive questionnaire, a locally validated household food security access scale, and the collection of anthropometric measurements by trained dietitians to increase the accuracy of data and reduce the risk of reporting bias. However, results from the present study need to be interpreted in the light of a number of limitations. The study sample is not representative of the Lebanese households in general, but rather of households that have children aged 4-18 years. Another limitation is the inability to report household income per capita in the present study given that income was collected as a categorical rather than a numerical variable. Future studies need to consider income per capita and to explore other socio-economic and neighbourhood characteristics when exploring correlates of household FI. The cross-sectional design of the study allowed us only to examine associations rather than explore potential causal pathways between FI and various sociodemographic characteristics and maternal and childhood nutritional status. FI was also measured at the household level and it may not reflect the severity of FI that is witnessed at the individual level. Nevertheless, every attempt was made to ensure that mothers, as proxy respondents, considered the food security of all household members when responding to these questions.

\section{Conclusion}

Findings from the present study show that the prevalence of FI was notably high among Lebanese households with 
children. Correlates of FI included crowding of the household, low parental educational attainment and unemployment. Although no associations were found between household FI and children's and mother's anthropometric measures after adjusting for sociodemographic correlates, both groups require particular attention. FI increases the risk for women and children to adopt unhealthy eating and lifestyle behaviours, which can have long-lasting effects on their overall health and well-being. Findings from the present study highlight the need for identifying households most vulnerable to FI and for devising evidence-based policies and programmes that can help promote more sustainable, resilient and healthier livelihoods.

\section{Acknowledgements}

Acknowledgements: The authors express their sincere gratitude to all participating households and acknowledge the efforts of the field coordinator (Ms Ruba Cheaib) and all the field workers who were involved in data collection as part of this national study. In addition, the authors would like to acknowledge Ms Marwa Diab El Harake and Ms Nada Adra for their assistance with data cleaning and statistical analyses. Financial support: This study was funded by the Lebanese National Council for Scientific Research and the University Research Board at the American University of Beirut. The funding organizations had no role in the design, data collection, analysis or writing of this manuscript. Conflict of interest: The authors declare that they have no conflict of interest. Authorship: L.J., F.N. and N.H. conceptualized the research design and study objectives; L.J. coordinated data collection, entry and analysis; F.N. and S.K. contributed significantly to data analysis and interpretation; L.J. acted as the lead author of the manuscript and N.H. provided critical review of the manuscript. All authors read and approved the final manuscript. Ethics of buman subject participation: The study was conducted in accordance with the Declaration of Helsinki and the protocol was approved by the Institutional Review Board at the American University of Beirut (NUT.LJ.03). Written informed consent was obtained from all individual participants included in the study.

\section{References}

1. Food and Agriculture Organization of the United Nations (1996) Report of the World Food Summit. http://www.fao. org/docrep/003/w3548e/w3548e00.htm (accessed June 2017).

2. Food and Agriculture Organization of the United Nations (2017) The State of Food Insecurity in the World. http:// www.fao.org/3/a-I7695e.pdf (accessed January 2018).

3. International Food Policy Research Institute (2015) 2014-2015 Global Food Policy Report. Chapter 7: Conflict and food insecurity. https://www.ifpri.org/sites/default/ files/gfpr/2015/feature_3086.html (accessed August 2018).
4. Breisinger C, Van Rheenen T, Ringler C et al. (2010) Food Security and Economic Development in the Middle East and North Africa: Current State and Future Perspectives. IFPRI Discussion Paper no. 00985. Washington, DC: International Food Policy Research Institute; available at https:// www.researchgate.net/profile/Tingju_Zhu/publication/ 254416793_Food_Security_and_Economic_Development_ in_the_Middle_East_and_North_Africa/links/Of31753b2cd 82ca88b000000.pdf

5. Breisinger C, Ecker O, Al-Riffai $\mathrm{P}$ et al. (2012) Beyond the Arab awakening: policies and investments for poverty reduction and food security. https://pdfs.semanticscholar. org/eca6/af30ba46db982d667db7e3e1f364529dcda6.pdf (accessed December 2017).

6. International Food Policy Research Institute (2015) 20142015 Global Food Policy Report. Chapter 9: Regional developments. https://www.ifpri.org/sites/default/files/ gfpr/2015/feature_3088.html (accessed August 2018).

7. World Food Programme (2017) Vulnerability assessment of Syrian refugees in Lebanon. https://reliefweb.int/report/ lebanon/vulnerability-assessment-syrian-refugees-lebanon2016 (accessed December 2017).

8. Ghattas H, Sassine AJ, Seyfert K et al. (2014) Food insecurity among Iraqi refugees living in Lebanon, 10 years after the invasion of Iraq: data from a household survey. $\mathrm{Br} \mathrm{J} \mathrm{Nutr}$ 112, 70-79.

9. Ghattas H, Sassine AJ, Seyfert K et al. (2015) Prevalence and correlates of food insecurity among Palestinian refugees in Lebanon: data from a household survey. PLoS One 10, e0130724.

10. Jomaa L, Naja F, Cheaib R et al. (2017) Household food insecurity is associated with a higher burden of obesity and risk of dietary inadequacies among mothers in Beirut, Lebanon. BMC Public Health 17, 567.

11. Sahyoun NR, Nord M, Sassine AJ et al. (2014) Development and validation of an Arab family food security scale. J Nutr 144, 751-757.

12. Bocquier A,Vieux F, Lioret $S$ et al. (2015) Socio-economic characteristics, living conditions and diet quality are associated with food insecurity in France. Public Health Nutr 18, 2952-2961.

13. Cordero-Ahiman OV, Santellano-Estrada E \& Garrido A (2018) Food access and coping strategies adopted by households to fight hunger among indigenous communities of Sierra Tarahumara in Mexico. Sustainability 10, 473.

14. Isanaka S, Mora-Plazas M, Lopez-Arana S et al. (2007) Food insecurity is highly prevalent and predicts underweight but not overweight in adults and school children from Bogota, Colombia. J Nutr 137, 2747-2755.

15. Shariff ZM \& Khor GL (2008) Household food insecurity and coping strategies in a poor rural community in Malaysia. Nutr Res Pract 2, 26-34.

16. Hanson KL \& Connor LM (2014) Food insecurity and dietary quality in US adults and children: a systematic review. $A m \mathrm{~J}$ Clin Nutr 100, 684-692.

17. Ivers LC \& Cullen KA (2011) Food insecurity: special considerations for women. Am J Clin Nutr 94, issue 6, 1740S-1744S.

18. Weaver LJ \& Hadley C (2009) Moving beyond hunger and nutrition: a systematic review of the evidence linking food insecurity and mental health in developing countries. Ecol Food Nutr 48, 263-284.

19. McDonald C, McLean J, Kroeun H et al. (2015) Household food insecurity and dietary diversity as correlates of maternal and child undernutrition in rural Cambodia. Eur J Clin Nutr 69, 242-246.

20. Frongillo EA \& Bernal J (2014) Understanding the coexistence of food insecurity and obesity. Curr Pediatr Rep $\mathbf{2}$, 284-290. 
21. Gundersen CG \& Garasky SB (2012) Financial management skills are associated with food insecurity in a sample of households with children in the United States. J Nutr 142 , 1865-1870.

22. Coleman-Jensen A, McFall W \& Nord M (2013) Food Insecurity in Households with Children: Prevalence, Severity, and Housebold Characteristics, 2010-11. Economic Information Bulletin no. EIB-113. Washington, DC: US Department of Agriculture, Economic Research Service.

23. Ali Naser I, Jalil R, Muda W et al. (2014) Association between household food insecurity and nutritional outcomes among children in Northeastern of Peninsular Malaysia. Nutr Res Pract 8, 304-311.

24. Saha KK, Frongillo EA, Alam DS et al. (2009) Household food security was associated with growth of infants and young children in rural Bangladesh - Corrigendum. Public Health Nutr 12, 884.

25. Schmeer KK \& Piperata BA (2017) Household food insecurity and child health. Matern Child Nutr 13, e12301.

26. Mohd Shariff Z, Lin KG, Sariman S et al. (2015) The relationship between household income and dietary intakes of 1-10 year old urban Malaysian. Nutr Res Pract 9, 278-287.

27. Piperata BA, Schmeer KK, Hadley C et al. (2013) Dietary inequalities of mother-child pairs in the rural Amazon: evidence of maternal-child buffering? Soc Sci Med 96, 183-191.

28. Central Administration of Statistics (2007) Population characteristics in 2007. http://www.cas.gov.lb/index.php/ demographic-and-social-en/population-en (accessed July 2017).

29. Naja F, Hwalla N, Fossian $T$ et al. (2015) Validity and reliability of the Arabic version of the Household Food Insecurity Access Scale in rural Lebanon. Public Health Nutr 18, 251-258.

30. Kish L (1949) A procedure for objective respondent selection within the household. J Am Stat Assoc 44, 380-387.

31. Melki I, Beydoun H, Khogali M et al. (2004) Household crowding index: a correlate of socioeconomic status and inter-pregnancy spacing in an urban setting. J Epidemiol Community Health 58, 476-480.

32. Nasreddine L, Naja F, Chamieh MC et al. (2012) Trends in overweight and obesity in Lebanon: evidence from two national cross-sectional surveys (1997 and 2009). BMC Public Health 12, 798.

33. Coates J, Swindale A \& Bilinsky P (2007) Household Food Insecurity Access Scale (HFIAS) for measurement of food access: indicator guide. https://www.fantaproject.org/mon itoring-and-evaluation/household-food-insecurity-accessscale-hfias (accessed June 2016).

34. World Health Organization (2000) Obesity: Preventing and Managing the Global Epidemic. Report of a WHO Consultation. WHO Technical Report Series no. 894. http:// www.who.int/nutrition/publications/obesity/WHO_TRS_ 894/en/ (accessed June 2018).

35. World Health Organization (2016) Global Database on Child Growth and Malnutrition. The WHO Anthro survey analyser. http://www.who.int/nutgrowthdb/software/en/ (accessed 23 May 2018).
36. World Health Organization (2008) Training Course on Child Growth Assessment: WHO Child Growth Standards. Interpreting Growth Indicators. http://www.who.int/child growth/training/module_c_interpreting_indicators.pdf (accessed February 2015)

37. McCarthy HD \& Ashwell M (2006) A study of central fatness using waist-to-height ratios in UK children and adolescents over two decades supports the simple message - keep your waist circumference to less than half your height'. Int J Obes (Lond) 30, 988-992.

38. Turrell G (2000) Income non-reporting: implications for health inequalities research. J Epidemiol Community Health 54, 207-214.

39. Bawadi HA, Tayyem RF, Dwairy AN et al. (2012) Prevalence of food insecurity among women in northern Jordan. $J$ Health Popul Nutr 30, 49-55.

40. Simsek H, Meseri R, Sahin S et al. (2013) Prevalence of food insecurity and malnutrition, factors related to malnutrition in the elderly: a community-based, cross-sectional study from Turkey. Eur Geriatr Med 4, 226-230

41. Tansel A \& Ozdemir ZA (2014) Determinants of transitions across formal/informal sectors in Egypt. http://ftp.iza.org/ dp8773.pdf (accessed June 2016).

42. Tarasuk V, Mitchell A \& Dachner N (2014) Household food insecurity in Canada, 2014. http://proof.utoronto.ca/wpcontent/uploads/2016/04/Household-Food-Insecurity-inCanada-2014.pdf (accessed July 2017).

43. Borch A \& Kiærnes U (2016) The prevalence and risk of food insecurity in the Nordic Region: preliminary results. J Consum Policy 39, 261-274.

44. World Bank (2016) Poverty and shared prosperity 2016: taking on inequality. https://openknowledge.worldbank. org/bitstream/handle/10986/25078/9781464809583.pdf (accessed July 2016)

45. United Nations Development Programme (2008) Living conditions of households 2007. http://www.lb.undp.org/ content/lebanon/en/home/library/poverty/living-condi tions-of-households-2007.html (accessed September 2017).

46. Kukrety N \& Al Jamal S (2016) Poverty, inequality and social protection in Lebanon. https://oxfamilibrary.openrepo sitory.com/handle/10546/594375 (accessed January 2016).

47. United Nations Development Programme (2014) Regional refugee \& resilience plan (2015-16): Lebanon. http:// reliefweb.int/report/lebanon/regional-refugee-resilienceplan-2015-16-lebanon (accessed July 2017).

48. Magaña-Lemus D, Ishdorj A, Rosson CP et al. (2016) Determinants of household food insecurity in Mexico. Agric Food Econ 4, 10.

49. Oddo VM, Bleich SN, Pollack KM et al. (2017) The weight of work: the association between maternal employment and overweight in low-and middle-income countries. Int $J$ Behav Nutr Phys Act 14, 66.

50. Franklin B, Jones A, Love D et al. (2012) Exploring mediators of food insecurity and obesity: a review of recent literature. J Commun Health 37, 253-264.

51. Central Administration of Statistics (2008) Demographic and social statistics. http://www.cas.gov.lb/index.php/demo graphic-and-social-en (accessed August 2017). 